\title{
Experimental evaluation of thermal comfort, IAQ indices and exposure to airborne contaminant in an Airborne Infection Isolation Room equipped with a displacement air distribution system \\ (pre-refereeing version)
}

\section{Abstract}

This study is focused in determine the convenience of the use of displacement ventilation strategy in airborne infection isolation rooms (AIIRs). Comfort of the occupants of the chamber, IAQ indices and the exposition of the health worker (HW) to the contaminants emitted by the confined patient $(\mathrm{P})$ are considered in a typical AIIR set up with a hot radiant wall representing an external wall. Three air ventilation rates are tested to determine their influence in the studied variables. Results show that IAQ indices associated with ventilation and general comfort indices for both manikins performs well in the cases studied. Lockup phenomenon associated to displacement ventilation occurs above $\mathrm{P}$ but it has a low influence on contaminant exposition of HW because of the influence of the convective boundary layer of HW. The influence of the radiant wall derives part of the fresh air directly to the exhaust and has a low influence the comfort of the manikins.

\section{Introduction}

Hospitals and medical facilities are suitable places for cross infection between their occupants [1-3], whether patients, health workers of visitors. Some of these infections could be transmitted through the air [4], pathogens can be transported from infected people and spread the illness. Pathogens can be found in droplets of different size that are emitted through respiratory exhalation processes [5,6] such breathing [7] coughing [8] and sneezing [9]. Once these droplets are released, they suffer an evaporative process that transform them into 
droplet nuclei [10-12]. Depending on the size of the resulting particle they can deposit quickly because of the effect of gravity, if their diameter is greater than $10 \mu \mathrm{m}$ [13], or be suspended following the ventilation induced effects, if their diameter is between 0.1 to 10 $\mu \mathrm{m}$. These small particles can be spread long distance and generate cross infections [10]. For example, transmission by small droplets or droplet nuclei $(<5 \mu \mathrm{m}$ diameter $)$ is the dominant mode for influenza spreading [14]. A convenient ventilation strategy can reduce the possibility of these infections [15].

Patients that develop an infectious disease that is found capable to be spread through air, and this way be considered a threat for the rest of occupants of the health facility, need to be confined in an isolated environment [16]. Airborne Infection Isolation Rooms (AIIR) are isolation spaces in hospitals provided with negative differential pressure respect of the rest of the building [17]. This way it can be assured that the pathogens emitted by the patient don't reach the rest of the building are ventilated using high renovation rates according to guides published by different National Health Committees [16,18-21].

These recommendations are based on the belief that high renovation rates could reduce cross infection risk between patients and health workers in such spaces by diluting and removing pathogens. Nevertheless, recent research focusses the attention in provide a good air distribution rather in maintain high renovation rates as the most important factor in reducing cross infection risk [22-24]. Thus, current strategies to reduce energy usage [25] in ventilation systems typically involve lowering airflow rates and/or heating/cooling capacity. This way and if the design it is not correctly resolved [25] the indoor air quality (IAQ) [26] and thermal comfort [27] can be compromised.

Maintain a comfortable environment [26] is important issue to be taken into account in designing AIIRs because patients have to stay long periods of time confined in these spaces 
[28]. Recent research has focused its attention in comfort in hospital environments, for both health workers [29] and patients [30,31] which usually spend a lot of time lying sleeping $[32,33]$. It has been determined that patients' thermal comfort [34,35] is reached at higher temperatures than in other environments. IAQ indices have been defined to evaluate both the ability of a system to exchange the air in the room and the ability of a system to remove airborne contaminants [14]. These values have been used widely used in recent ventilation studies to determine how ventilation can dilute and remove pathogens and this way reduce cross infection risk of health workers [22,36,37].

Different ventilation strategies can be used in AIIR indoor environments [12], while the most widely applied is mixing ventilation (MV) [38]. However, this strategy can reduce thermal comfort in the occupied zone of the ventilated space and can spread contaminants and pathogens [39]. In recent times displacement ventilation, DV, has arisen as an alternative ventilation strategy to improve both the thermal comfort and IAQ of the occupied space. The inward air flow is delivered at low velocity using diffusers placed at relative low height, when this slow moving air mass encounters a heat load, it rises and carries the heat and pollutants towards the ceiling [40,41]. This strategy is used extensively in different ventilation applications and its use is particularly recommended for high renovation rates requirement applications [42] such AIIR. Well-designed DV systems has been found to be especially effective in removing contaminants $[12,43,44]$.

Tracer gas technique is recommended [15] and has been used extensively to analyze ventilation effectiveness and contaminant removal in indoor places by determining IAQ indices $[37,45]$. This technique has also been used to determine cross infection risk between people in inward environments [46-49]. Tracer gases are seeded in the air simulating the presence of pathogens. Its concentration in a definite location is used to determine pathogens exposition and hence cross infection risk in that point. This technique has been also validated 
by comparing with tracer aerosol particles technique $(1 \mu \mathrm{m}$ to $3 \mu \mathrm{m})$ giving a good agreement close to the source of contaminants [49].

This study is intended to experimentally analyze the use of DV strategy resolving some the limitations found in other ventilation studies. Exhalation of the lying thermal manikin is considered the source of contaminants in this study. These contaminants are seeded completely mixed with the breathing exhalation air flow. This method is considered a more realistic way to perform than other approaches carried out previously $[45,49]$. This can be important in the study of low velocity ventilation flows systems such as DV [50,51]. This study implements a radiant panel on a wall representing an external wall. The load of this wall can have an important influence on a thermally driven ventilation system such DV [45] that need to be considered. Three air ventilation rates ranging from $3 \mathrm{ACH}$ to $12 \mathrm{ACH}$ are considered in this study. Most of the experimental ventilation studies in hospital rooms consulted to date test air ventilation rates under $12 \mathrm{ACH}[18,46,50,51]$. The ones that test air ventilation rates of $12 \mathrm{ACH}$ or higher don't use DV [37,52]. nevertheless all the different national committees recommendations consulted about this issue recommend higher ventilation rates for such spaces, $9 \mathrm{ACH}$ in the case of Canada, $12 \mathrm{ACH}$ in the case of USA, UK, Japan and Denmark [18] and even reach $15 \mathrm{ACH}$ in the case of Australia [19,53].

This paper presents an experimental an analysis of the use of DV strategy in AIIR as an alternative to the most extended MV strategy, using a typical AIIR set up. The objectives of this investigation are, for three different high air ventilation rates, (1) to assess the thermal comfort for a typical AIIR by using DV (2) to analyze ventilation performance IAQ indices and (3) determine contaminant exposition and cross infection risk by studying local mean exposition, local peak exposure, its frequency and effective contaminant intake for health workers (HW) being the only source of contaminants the exhalation of the patient $(\mathrm{P})$. This way the convenience of the use of DV strategy in AIIRs can be evaluated. 


\section{Methods}

\subsection{Test room and experimental setup}

This study was carried out in an experimental chamber within the HVAC (heating, ventilation and air-conditioning systems) laboratory at the University of Cordoba. The experimental setup corresponds to a typical AIIR, which consists of a room $4.50 \mathrm{~m}$ length, $3.3 \mathrm{~m}$ width, and $2.8 \mathrm{~m}$ height. Two breathing thermal manikins located inside the chamber represent a lying patient over a hospital bed (P) and a health worker standing close to the first one (HW), (Figure 1).
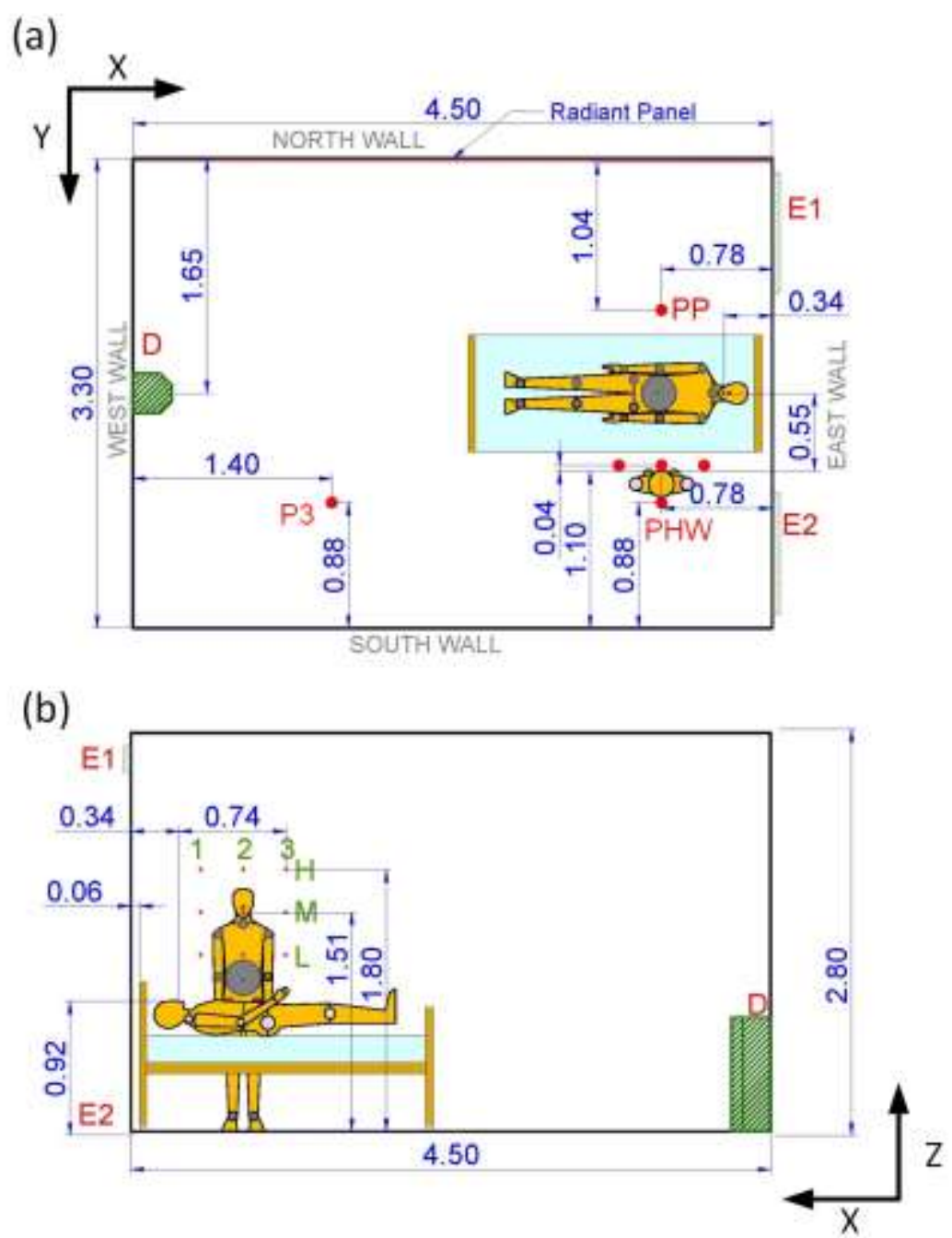

Figure 1. (a) Plan view of the test room. Displacement air diffuser (D); Exhaust grilles (E); Vertical Poles (PP, PHW and P3). (b) Profile view of the test room. Displacement air diffuser (D); Exhaust Grilles (E); Columns of the point matrix of tracer gas measurements (1, 2 and 3); Rows of the point matrix of tracer gas measurements $(\mathrm{H}, \mathrm{M}, \mathrm{L})$ 


\subsection{Thermal loads and breathing thermal manikins}

The two breathing thermal manikins have the same geometry, with a height of $1.70 \mathrm{~m}$ and a surface of $1.6 \mathrm{~m}^{2}$ [7,54]. Each breathing thermal manikin has four independent thermal zones: head, arms, trunk and legs. The total sensible heat emitted for each manikin is obtained from the ASHRAE Fundamentals Handbook [55] according to the metabolic rate of 1 in the case of the standing manikin (HW) and 0.7 in the case of the lying manikin (PP). The distribution of the total sensible heat is set according to Tanabe [56], as shown in Table 1.

Table 1. Thermal loads in the experimental chamber.

\begin{tabular}{|c|c|c|c|c|}
\hline \multirow{2}{*}{\multicolumn{3}{|c|}{$\begin{array}{l}\text { Source } \\
\text { Radiant Panel }\end{array}$}} & \multicolumn{2}{|c|}{ Load (W) } \\
\hline & & & & 500 \\
\hline \multirow{5}{*}{ HW manikin } & \multirow{4}{*}{ Body } & Head & 5.6 & \multirow{5}{*}{85} \\
\hline & & Arms & 14.4 & \\
\hline & & Trunk & 19.2 & \\
\hline & & Legs & 40.8 & \\
\hline & \multicolumn{2}{|c|}{ Breathing } & 5 & \\
\hline \multirow{5}{*}{$P$ manikin } & \multirow{4}{*}{ Body } & Head & 4.9 & \multirow{5}{*}{75} \\
\hline & & Arms & 12.6 & \\
\hline & & Trunk & 16.8 & \\
\hline & & Legs & 35.7 & \\
\hline & \multicolumn{2}{|c|}{ Breathing } & 5 & \\
\hline \multicolumn{4}{|l|}{ Total } & 660 \\
\hline
\end{tabular}

An external heat gain in the north wall of $500 \mathrm{~W}$ is imposed by means of a hydronic wall radiant system. The radiant panel emits a heat flux of $33.67 \mathrm{~W} / \mathrm{m}^{2}$ and maintains a mean inner surface temperature of $29.1^{\circ} \mathrm{C}$ in the north wall of the chamber. The rest of the walls of the chamber are considered adiabatic as the chamber is inside a lab at the same temperature.

The HW manikin emits $80 \mathrm{~W}$ through its body and $5 \mathrm{~W}$ through its breathing, while the P manikin emits $70 \mathrm{~W}$ through its body and $5 \mathrm{~W}$ through its breathing. 
The breathing thermal manikins have their own independent breathing system that can simulate different breathing flows. Breathing function has been calculated following the studies carried out by Gupta [57] who obtained that the breathing function of a subject is dependent of its gender, its weight and its height. In this study both manikins perform the same breathing function obtained considering a male $1.70 \mathrm{~m}$ tall and $70 \mathrm{~kg}$ weight. The resulting breathing function characteristics can be seen at Table 1 .

Table 2. Breathing function characteristics.

\begin{tabular}{|c|c|c|c|}
\hline \multicolumn{2}{|c|}{ Respiration frequency $\left(\mathbf{m i n}^{-\mathbf{1}}\right)$} & \multirow{2}{*}{$\begin{array}{c}\text { Minute } \\
\text { volume (L/min) }\end{array}$} & $\begin{array}{c}\text { Tidal } \\
\text { volume (L) }\end{array}$ \\
\cline { 1 - 2 } In & Out & 9.46 & 0.55 \\
\hline 17.90 & 16.43 &
\end{tabular}

HW inhales through the nose while the P exhales through the mouth. HW does not exhales air to the experimental chamber while $\mathrm{P}$ does not inhale air from the experimental chamber. This way P manikin can be considered the only source of contaminants in the experimental chamber in contaminant exposition experiments while HW can be considered the target where the contaminant exposition is measured. Exhalation of PP is situated at a relative height of $\mathrm{z} / \mathrm{H}=0.325$ while the inhalation point of $\mathrm{HW}$ it is located at $\mathrm{z} / \mathrm{H}=0.539$, as can be observed at Figure 1.

The total thermal loads present in the room during the experiments, considering the thermal radiant panel $(500 \mathrm{~W})$ and the thermal manikins $(160 \mathrm{~W})$ reach $660 \mathrm{~W}$, which corresponds to $44.44 \mathrm{~W} / \mathrm{m}^{2}$.

\subsection{Ventilation system}

Clean air is supplied through a displacement diffuser, D, located in the west wall of the chamber and extracted by two exhaust grilles, E1 and E2, located in the upper part of the east wall of the chamber (Figure 1). 
The ventilation system has been set at three different air change rates of 6,9 and $12 \mathrm{ACH}$, supplying air at $18.2^{\circ} \mathrm{C}, 20.6^{\circ} \mathrm{C}$ and $21.8^{\circ} \mathrm{C}$ respectively to maintain a mean temperature in the occupied zone of $25 \pm 1{ }^{\circ} \mathrm{C}$. A summary of the conditions of the three tests performed can be seen at Table 3 .

Table 3. Tests performed

\begin{tabular}{|c|c|c|c|}
\hline Tests & $\begin{array}{c}\text { Renovation } \\
\text { Rate }(\mathbf{A C H})\end{array}$ & $\begin{array}{c}\text { Supply air } \\
\text { flow rate } \\
\left(\mathbf{m}^{\mathbf{3}} / \mathbf{h}\right)\end{array}$ & $\begin{array}{c}\text { Supply air } \\
\text { temperature }\left({ }^{\circ} \mathbf{C}\right)\end{array}$ \\
\hline Test 1 & 6 & 250 & 18.2 \\
\hline Test 2 & 9 & 375 & 20.6 \\
\hline Test 3 & 12 & 500 & 21.8 \\
\hline
\end{tabular}

\subsection{Measuring instruments}

Three vertical poles (PHW, PP and P3) are located inside the experimental chamber (Figure 1). PHW and PP are close to HW manikin and P manikin respectively. P3 is placed far from the breathing thermal manikins. Along their length, temperature, humidity and air velocity probes are disposed as can be seen at Table 4 .

Table 4. Probes position along the height of each poles

\begin{tabular}{|c|c|c|c|}
\hline $\begin{array}{c}\text { Height } \\
\text { (m) }\end{array}$ & P3 Pole & PHW Pole & PP Pole \\
\hline 2.3 & $\mathrm{~T}_{\mathrm{a}}$ & $\mathrm{T}_{\mathrm{a}}, \mathrm{V}_{\mathrm{a}}$ & $\mathrm{T}_{\mathrm{a}}, \mathrm{V}_{\mathrm{a}}$ \\
\hline 1.7 & $\mathrm{~T}_{\mathrm{a}}$ & $\mathrm{T}_{\mathrm{a}}, \mathrm{V}_{\mathrm{a}}, \mathrm{HR}$ & $\mathrm{T}_{\mathrm{a}}, \mathrm{V}_{\mathrm{a}}, \mathrm{HR}, \mathrm{T}_{\text {globe }}$ \\
\hline 1.1 & $\mathrm{~T}_{\mathrm{a}}$ & $\mathrm{T}_{\mathrm{a}}, \mathrm{V}_{\mathrm{a}}$ & $\mathrm{T}_{\mathrm{a}}, \mathrm{V}_{\mathrm{a}}$ \\
\hline 0.6 & $\mathrm{~T}_{\mathrm{a}}$ & $\mathrm{T}_{\mathrm{a}}, \mathrm{V}_{\mathrm{a}}$ & $\mathrm{T}_{\mathrm{a}}, \mathrm{V}_{\mathrm{a}}$ \\
\hline 0.1 & $\mathrm{~T}_{\mathrm{a}}$ & $\mathrm{T}_{\mathrm{a}}, \mathrm{V}_{\mathrm{a}}$ & $\mathrm{T}_{\mathrm{a}}, \mathrm{V}_{\mathrm{a}}$ \\
\hline
\end{tabular}

Ambient temperature probes $\left(\mathrm{T}_{\mathrm{a}}\right)$ consist of J-type thermocouples, with an accuracy of $2 \%$ at the considered temperature range $\left(15-45^{\circ} \mathrm{C}\right)$. These air temperature sensors are protected from radiation by a cylindrical reflective metal device. Absolute air velocity $\left(\mathrm{V}_{\mathrm{a}}\right)$ is measured using hot-sphere anemometers (TSI Air Velocity Transducer 8475, TSI, Minnesota). These probes can measure an instantaneous velocity range from 0.02 to $2.5 \mathrm{~m} / \mathrm{s}$ with a calibration 
accuracy of $3 \%$. Ambient relative humidity $\left(\mathrm{HR}_{\mathrm{a}}\right)$ has been measured using air humidity sensors (HMT100, Vaisala, Finland) with a calibration accuracy of 1.7\%.

Inner surface temperature of all the enclosures has been also measured during the tests. 15 resistive temperature probes (PT100, TC Direct, UK) have been distributed for all the internal wall surfaces of the chamber. These sensors have been calibrated in the range between $15^{\circ} \mathrm{C}$ and $40{ }^{\circ} \mathrm{C}$ in order to assure an uncertainty of measurement of $\pm 0.3{ }^{\circ} \mathrm{C}$. Radiant temperature is calculated by using these inner surface temperatures and the method B.4.2 of EN ISO 7726 standard [58]. A globe temperature probe $\left(\mathrm{T}_{\text {globe }}\right)$ has been placed along the PP pole (Table 4) to compare radiant temperature obtained by using Method B.4.2 and the obtained by Method B.2 from ISO 7726 standard [58]. The globe is a black sphere of $150 \mathrm{~mm}$ diameter (SFTSCB-10-6-100, KIMO, France) at the center of which is the temperature probe, a J-Type thermocouple with an accuracy of $2 \%$ in the range of $15-45^{\circ} \mathrm{C}$. The comparative is added as additional information in Supporting Information A.

Tracer gas equipment is used to measure the exposition of manikin HW to the contaminants exhaled by manikin P. R134a is used as a tracer gas [45,59]. To dose the tracer gas emitted through $\mathrm{P}$ exhalation and measure the presence of tracer gas in the surroundings of the HW manikin a multipoint sampler and doser (Innova 1303, LumaSense Technologies, California) together with a photoacoustic gas monitor (Innova 1412, LumaSense Technologies, California) are used.

\subsection{Thermal comfort indices}

Temperature, air velocity, and humidity data obtained from the poles PP and PHW together with the radiant temperature obtained from the inner surface temperature of the internal chamber enclosures are used to determine different comfort indices for the position of $\mathrm{P}$ and HW following the procedures detailed in ISO EN 7730 [35]. 
Operative temperature $\left(\mathrm{T}_{\mathrm{O}}\right)$ as environmental index to evaluate thermal comfort has been obtained for P and HW. Global comfort is determined by obtaining the values of Predicted mean vote (PMV) and predicted percentage of dissatisfied (PPD). These values are obtained for a standing person in the position of HW and a sitting person in the position of $\mathrm{P}$ after steady state conditions are obtained in the experimental room. Current standard does not provide a method to obtain such indices for a lying person, so the closest body posture has been selected. A clothing insulation of 0.5 clo has been selected for both manikins according to the usual clothing conditions in hospitals. The metabolic activity considered for HW manikin is the corresponding with a standing person performing light activity while $\mathrm{P}$ manikin is considered seated, quiet. Asymmetric thermal radiation as a source of thermal discomfort has been studied for $\mathrm{P}$ and HW positions by obtaining the value of its value between the walls North, where the radiant wall is located, and South $\left(\Delta \mathrm{T}_{\mathrm{prN}-\mathrm{S}}\right)$. The temperature difference between head and feet level $\left(\Delta \mathrm{T}_{\mathrm{h}-\mathrm{f}}\right), 1.1 \mathrm{~m}$ and $0.1 \mathrm{~m}$ above the floor in the case of $\mathrm{P}$ and 1.7 and $0.1 \mathrm{~m}$ in the case of $\mathrm{HW}$ is also obtained.

\subsection{Ventilation performance IAQ indices}

Two ventilation performance IAQ, widely used in the research literature $[15,60,61]$ indices have been obtained by using tracer gas technique for the conditions of the three tests performed, air change efficiency $\left(\varepsilon^{a}\right)$ and local air change index $\left(\varepsilon_{P}^{a}\right)$. These indices are defined as:

$$
\begin{aligned}
\varepsilon^{a} & =\frac{\tau_{n}}{\tau_{P}} \cdot 100 \#(1) \\
\varepsilon_{P}^{a} & =\frac{\tau_{n}}{2 \cdot \tau_{e}} \cdot 100 \#(2)
\end{aligned}
$$

Where $\tau_{n}$ is the nominal time constant, $\tau_{p}$ is the age of the air in a local point and $\tau_{e}$ is the age of the air in the exhaust. These indices have been obtained by using the step down method [15] using $40 \mathrm{ppm}$ as the initial concentration. Supply air, as the only source of contaminant in the camber in this experiment, is seeded with tracer gas setting ventilation 
system into a configuration of full recirculation until the selected concentration is achieved. After that, seeding is stopped and the ventilation system operates again at $100 \%$ outside air and the decay curve of contaminant is registered. Contaminant is registered in the exhaust grilles to obtain $\varepsilon^{a}$ and in three different points in the surroundings of HW breathing area, $\mathrm{M} 1, \mathrm{M} 2$ and M3 to obtain $\varepsilon_{P}^{a}$.

\subsection{Contaminants distribution}

The distribution of contaminants emitted through the exhalation of $\mathrm{P}$ manikin has been studied under the conditions of the three tests carried out. Each experiment is performed stationary during 6 hours after steady state conditions are obtained in the experimental room. Manikin P inhales clean air from the exterior of the experimental chamber. Then, tracer gas is injected into the breathing system of manikin P. This manikin exhales air inside the experimental chamber with the contaminant completely mixed. The concentration of tracer gas in the manikin P exhalation flow is $7382.28 \mathrm{ppm}$ of R134A. As this refrigerant gas is not naturally present in the atmosphere, and the ventilation system operates at $100 \%$ outside air, any molecule that is measured inside the experimental chamber must have been emitted by $\mathrm{P}$ exhalation.

In order to determine the general contaminant removal performance of the ventilation system configuration, contaminant removal effectiveness $\left(\varepsilon^{c}\right)$ is obtained. This value has been used in different recent research $[45,59,62,63]$ and is defined as:

$$
\varepsilon^{c}=\frac{c_{e}-c_{s}}{<c>-c_{s}} \#(3)
$$

Where $c_{e}$ is the average concentration of the exhaust air, $c_{S}$ is the average concentration in the supply air, $\langle c\rangle$ is the mean concentration of contaminant of the chamber. The concentration in the supply air $\left(c_{S}\right)$ is registered but its value is always null because the tracer gas used is not naturally in the atmosphere. The mean concentration in the chamber $(\langle c\rangle)$ 
is obtained after the stationary experiment finish. In that moment, ventilation system is shut down as well as the tracer gas seeding into the chamber while the air inside the experimental chamber is completely mixed using an auxiliary fan. The concentration values obtained from all the measurement points inside the chamber are averaged during at least $15 \min$ to obtain the mean contaminant concentration value.

The exposition to contaminants around the breathing point of HW is determined through the local contaminant exposition $\left(e_{P}^{c}\right)$ index. This value has been used in similar research papers $[24,64-67]$ and is defined as:

$$
e_{P}^{c}=\frac{c_{i}-c_{s}}{c_{e}-c_{s}} \#(4)
$$

Where $c_{i}$ is the average concentration in a determined point inside the chamber.

Tracer gas concentration $\left(c_{i}\right)$ is measured inside the chamber to obtain $e_{P}^{c}$ in 10 different points around HW microenvironment. 9 points distributed in a vertical plane in front of HW manikin allocated in a $3 \times 3$ matrix, separated $4 \mathrm{~cm}$ from the $\mathrm{HW}$ inhalation point as can be seen at Figure 1 (a) and an extra point inside the inhalation airway (Inh) of HW breathing.

Local contaminant exposition is a useful value to determine contaminant exposition during the whole experiment. However, to analyze peak exposure to contaminants in such points, a new index, the local maximum exposure coefficient $\left(e_{P, \max }^{c}\right)$ is defined as follows:

$$
e_{P, \max }^{c}=\frac{c_{i, \max }-c_{s}}{c_{e}-c_{s}} \#(5)
$$

Where $c_{i, \max }$ is the average of the maximum values registered in a measurement point. A concentration measurement register is considered as a maximum if its value exceeds a $25 \%$ the average concentration. The frequency of such events has been also registered in time for 
each experiment $\left(f_{e_{P, \text { max }}^{c}}\right)$, this way the possibility having a peak concentration can be compared for the tests carried out.

The concentration obtained in the inhalation of $\mathrm{HW}$ is the effective contaminants intake of this manikin. Its value is referred to the average concentration emitted by the source, $\mathrm{P}$ manikin exhalation, to define the intake fraction $(I F)$ index [63]. Its value is thus obtained as:

$$
I F=\frac{\int Q_{b, i n h} c_{i n h} \mathrm{~d} t}{\int Q_{b, e x h} c_{e x h} \mathrm{~d} t}=\frac{c_{i n h}}{c_{\text {exh }}} \#(6)
$$

Where $Q_{b, \text { inh }}$, and $Q_{b, \text { exh }}(1 / \mathrm{min})$ are the breathing rate of $\mathrm{HW}$ (Target) and $\mathrm{P}$ (Sorce) manikins respectively $(1 / \mathrm{min})$ whose are the same for this study, $c_{i n h}$ is the average contaminant concentration inside the inhalation airways of the $\mathrm{P}$ manikin and $c_{\text {exh }}$ is the average contaminant concentration emitted through the HW exhalation.

IAQ guides [15] defines the local air quality index to determine localized contaminant removal ventilation system performance. This value is defined as the inverse of local contaminant exposition defined in this study.

\subsection{Smoke test}

Smoke visualization experiments have been carried out to determine supply air distribution inside the experimental chamber. These three experiments have been carried out under the three test conditions considered in this study once the environment conditions have reached its stationary state. Smoke is introduced into the room through the displacement diffusor completely mixed with supply air (Figure 1) during $60 \mathrm{~s}$. Smoke is created by a smoke machine (F2010Plus, Safex, Germany) using its standard fog fluid (Normal Power Mix, Safex, Germany). The images are recorded using a digital camera (DSC-H50, SONY, Japan). 
The videos of the smoke distribution inside the room are added as Supporting Information to this paper.

\section{Results and discussion}

\subsection{Experimental conditions}

Temperature is registered at five different heights in three different locations using vertical poles PHW, PP and P3. The dimensionless value of the temperature has been obtained taking into account the average value of the temperature measurements $\left(\mathrm{T}_{\mathrm{a}}\right)$, the supply average air temperature $\left(T_{s}\right)$, and the exhaust average air temperature $\left(T_{e}\right)$. Dimensionless temperatures for each pole are shown in Figure 2.

(a)

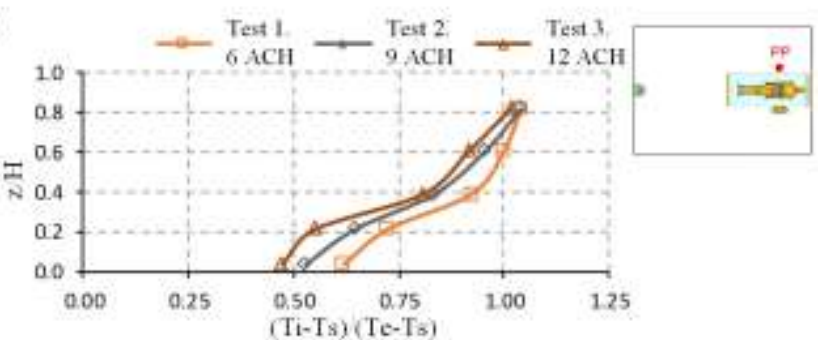

(b)

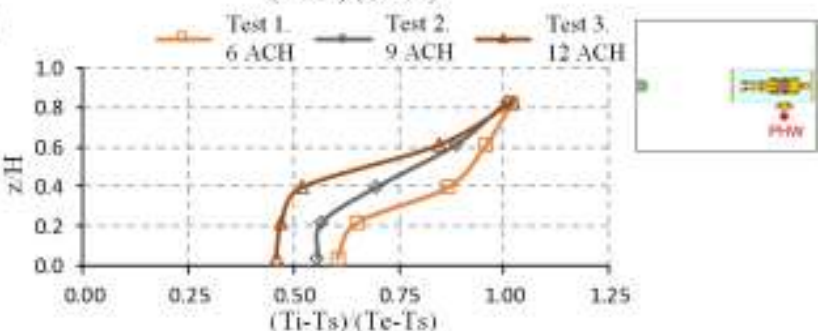

(c)

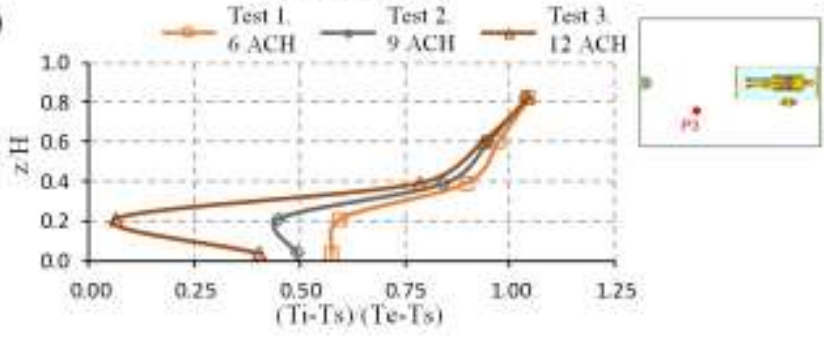

Figure 2. Dimensionless temperature at different heights. (a) Pole PP. (b) Pole PHW. (c) Pole P3.

Temperature profiles show the general temperature distribution along the height of the room. It can be noticed that the temperature at the higher measured height of the chamber is the same for the thee ventilation set ups considered. This is because the exhaust grilles are 
situated close to the ceiling of the room and the supply air temperature has been selected to balance internal loads and obtain the same exhaust temperature. It can be observed too that the increase of air ventilation rate leads to temperature profiles displaced to lowest temperatures, especially in the lower part of the chamber. This is because an increase of the air flow rate makes the fresh ventilation air stay less time in contact with the thermal loads and hence it cannot be heated as much as it is when lower ACHs are used.

A detail observation of the thee considered temperature profiles reveals that they show a different behavior along their height. The pole PP (Figure 2 (a)) is the closest pole to the radiant panel, which represents the main thermal load present into the experimental chamber, and because of its influence shows a continuous positive temperature gradient along its height. Likewise, P3 pole (Figure 2 (c)) temperature profile is influenced at high renovation rates by the air flow from the displacement diffuser, showing a temperature decrease in the probes affected by the displacement diffusor throw. Although, PHW pole (Figure 2 (b)) is far from any external perturbation source, showing a temperature profile than can be considered representative of the two thermal manikins occupied zone. It shows a nearly vertical temperature profile at the lower part of the room for the three experiments carried out, which reach a higher height with the increase of the air ventilation rate, and afterwards a sudden positive temperature gradient, which shows a higher slope the higher is the air ventilation rate. This positive temperature gradient starts in $\mathrm{z} / \mathrm{H}=0.2$ in Test 1 and Test 2 while it starts in $\mathrm{z} / \mathrm{H}=0.4$ in Test 3 . Taking into account the positions of the breathing points of the thermal manikins $(\mathrm{P}, \mathrm{z} / \mathrm{H}=0.325 ; \mathrm{HW} \mathrm{z} / \mathrm{H}=0.539)$, it can be presumed that this positive temperature gradient is developed in the heights between the two breathing points.

\subsection{Smoke tests}

Smoke test were performed for the three tests carried out in this study. The three videos taken during the three experiments carried out are shown as Supporting Information. One 
photograph is shown in Figure 3 during one of these tests was taken to illustrate supply air ventilation behavior.

(a) $\mathrm{t}=91 \mathrm{~s}$

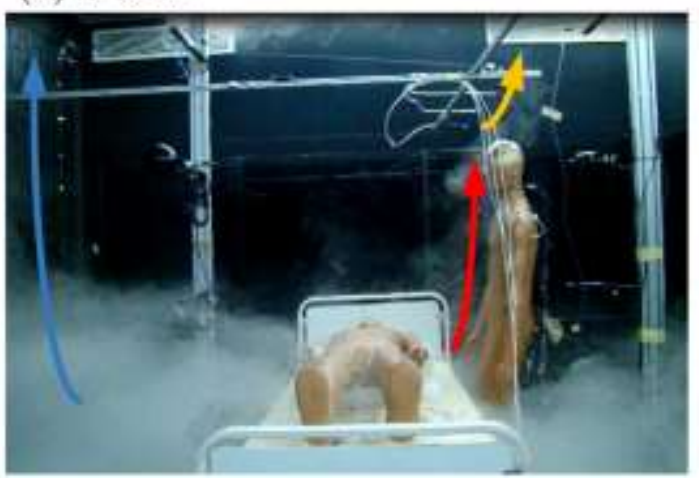

(b) $\mathrm{t}=165 \mathrm{~s}$

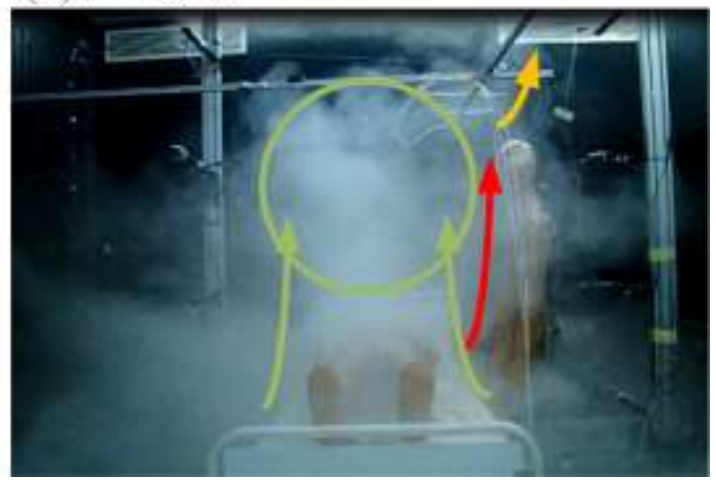

Figure 3. Smoke test pictures taken under the conditions of Test 1 . The red arrow marks the supply air caught by the thermal plume of HW manikin while the blue arrow marks the fraction of the supply air that is dragged by natural convection though the North radiant wall. Time since smoke is introduced in the chamber is shown in the photographs

Supply air ventilation behaves the same way for the three tests carried out. Though the dynamics of the process are faster the higher is the ventilation rate. Supply air is introduced in the chamber through the displacement diffusor and advances though the floor of the room in radial form from this point though North, South and East walls (Figure 1) gaining height with the distance to the diffusor as it is supposed in displacement ventilation [60]. When the flow reaches the North wall, equipped with a radiant heating panel, the flow advances fast through the wall reaching the ceiling quickly, the blue arrow in Figure 2 (a) marks this phenomenon. Once the flow reaches the ceiling the smoke is displaced through the exhaust grilles in the upper part of the East wall. This flow doesn't reach the occupied zone of the room. The rest of the supply air reaches the occupied zone of the room and the time it reaches the legs of HW advances through its body captured by the thermal boundary layer, red arrow in Figure 2 and is dragged upwards until once it leaves behind the head of the manikin forms a thermal plume, orange arrow in Figure 2 . Another thermal plume $[68,69]$ is created when the supply air reach the body of P manikin as can be seen at Figure 2 (b), represented by the green arrows. This time the flow is locked in its ascension and is stacked up above the height of HW, green circle in Figure 2 (b). This is caused by the intense slope of the positive 
temperature gradient at these heights that generates a lock-up phenomenon $[66,70]$. This situation could stop the same way the natural convection rise of the contaminants exhaled by $\mathrm{P}$ and therefore increase the contaminants concentration above the body of $\mathrm{P}$.

\subsection{Thermal Comfort}

Different indices to estimate the thermal comfort have been obtained. Results are shown in Figure 4 (a).

(a)

\begin{tabular}{|c|c|c|c|c|c|c|c|}
\hline & \multirow[b]{2}{*}{ Units } & \multicolumn{3}{|c|}{ HW } & \multicolumn{3}{|c|}{$\mathbf{P}$} \\
\hline & & $\begin{array}{c}\text { Test1 } \\
6 \mathrm{ACH}\end{array}$ & $\begin{array}{l}\text { Test } 2 \\
9 \mathrm{ACH}\end{array}$ & $\begin{array}{c}\text { Test } 3 \\
12 \text { ACH }\end{array}$ & $\begin{array}{c}\text { Test1 } \\
6 \mathrm{ACH}\end{array}$ & $\begin{array}{l}\text { Test } 2 \\
9 \text { ACH }\end{array}$ & $\begin{array}{c}\text { Test } 3 \\
12 \mathrm{ACH}\end{array}$ \\
\hline $\mathbf{T}_{\theta}$ & $\mathrm{C}$ & 25.2 & 25.0 & 24.8 & 25.6 & 25.6 & 25.2 \\
\hline PMV & + & 0.62 & 0.53 & 0.52 & -0.42 & -0.55 & -0.54 \\
\hline PPD & $\%$ & 13.1 & 11.0 & 10.7 & 11.3 & 11.2 & 19.1 \\
\hline$\Delta T_{p r} \times s$ & $\mathrm{~K}$ & 0.9 & 0,9 & 1.1 & 2.7 & 2.6 & 2.9 \\
\hline AThr & $\mathrm{K}$ & 2.4 & 1.5 & 1.1 & 2.7 & 1.4 & 1.9 \\
\hline
\end{tabular}

(b)

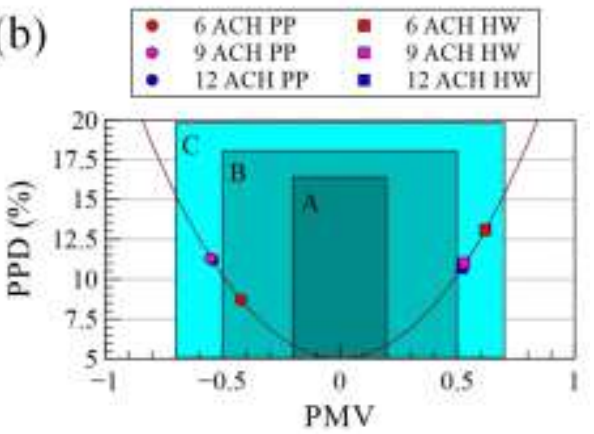

Figure 4. (a) General and local thermal comfort indices; (b) Predicted percentage of dissatisfied as a function of predicted mean vote.

According to the results obtained, operative temperature decreases with the air renovation rate for $\mathrm{P}$ and $\mathrm{HW}$ because of the increase of the ambient air velocity inside the chamber originated by the increase of ventilation flow rate. The values obtained are situated into the comfort zone for summer clothing and sedentary activity for low relative humidity situations. The increase of the ventilation sets operative temperature far from the zone of discomfort, so an increase of air renovation rate improves thermal comfort in terms of operative temperature.

The presence of the radiant panel in the North wall of the chamber creates a significant radiant temperature asymmetry for the N-S plane in all the cases considered. This radiant temperature asymmetry is higher in the PP position than in the HW position because of the geometric proximity with the radiant wall. The temperature asymmetry increases with the air renovation rate for all the tests performed. This increase of ventilation rate increments air 
velocity inside the chamber and this way promotes forced convection in all the chamber walls reducing their surface temperature. This phenomenon is less evident in the north wall, equipped with the radiant panel. Thus, the radiant temperature asymmetry for the N-S plane increases. Temperature difference between the head and feet level decrease with the increase of air ventilation rate. This is because an increment in the ventilation rate promotes temperature homogeneity in the occupied zone of the chamber.

General thermal comfort indices have been plotted in Figure 4 (b), where thermal comfort categories are defined according to the standard EN ISO 7730 [29]. However, it can be easily checked that the comfort indices PMV for PP and HW differs in all the cases studied. On the one hand, PMV indices for PP reflects a slightly cold sensation, being always situated between the comfort categories $\mathrm{B}$ and $\mathrm{C}$ depending on the test. On the other hand, PMV indices for HW shows a slightly hot sensation. In this case the comfort category is always C. This situation reflects that the two occupants have different thermal sensations in the same ambient conditions. This could be problematic because the relatively hot sensation of HW can discourage the use of personal protective equipment and thus limit its effectiveness [71].

\subsection{Ventilation measurements}

Air change efficiency has been obtained for three different case studies. Local air change efficiency has been also calculated in three different points placed at the height of HW inhalation (M). Results are shown in Figure 5. 

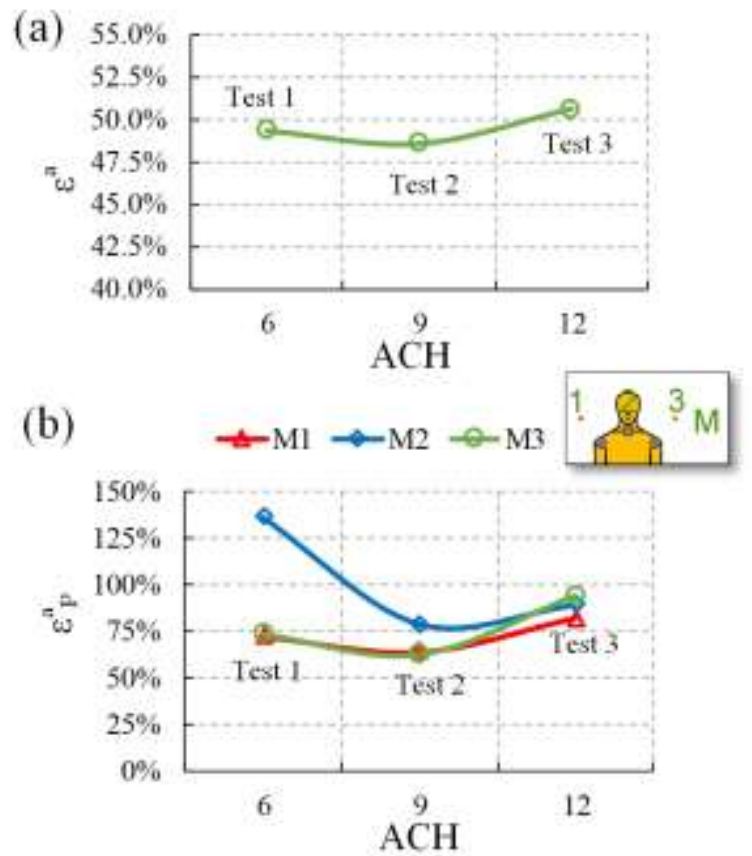

Figure 5. IAQ ventilation indices for the three experiments carried out. (a) Air change efficiency; (b) Local air change index. According to the results obtained, air change efficiency $\varepsilon^{a}$, Figure 5 (a), remain close to the $50 \%$ for all the three tests performed. Nearly no variation is perceived between Test 1 and Test 2 and a small increment of its value is perceived in Test 3. Perfect mixing ventilation is supposed to present values around 50\% while displacement ventilation is supposed to obtain values between $50 \%$ and $100 \%$ [15]. This value is representative of how the ventilation system replaces the air of the chamber. Thus, it can be noted that for the air renovation rates tested system is not performed as well as it was expected.

Local air change index $\left(\varepsilon_{P}^{a}\right)$, Figure $5(\mathrm{~b})$, tendency for the three points considered in the surroundings of HW microenvironment, have a different behavior depending on test conditions and their relative position with respect to HW inhalation point. In M1 and M3 measuring points, placed one on each side of the inhalation point of $\mathrm{HW}, \varepsilon_{P}^{a}$ values under the three test conditions considered present a similar tendency. $\varepsilon_{P}^{a}$ reduces its value lightly form Test 1 to Test 2 while it increases greatly from Test 2 o Test 3 , being $\varepsilon_{P}^{a}$ values always lower than $100 \%$. Although, the point M2 show a different tendency of its values under the same 
test conditions. Under Test 1 conditions $\varepsilon_{P}^{a}$ reach a value substantially higher than $100 \%$. In Test 2 its value decreases to around $75 \%$ but it is still higher than the registered $\varepsilon_{P}^{a}$ values for M2 and M3. Finally, under Test 3 conditions $\varepsilon_{P}^{a}$ for M1, M2 and M3 register similar values. This discordance between the values obtained for $\varepsilon_{P}^{a}$ in M2 point with respect to the other points considered is due to the convective boundary layer that brings fresh air from the lower part of the room. Its effect is more evident when the air ventilation rate in the room remains at low values [68]. In this study, this situation is added to the fact that the displacement ventilation throw of fresh air reaches higher heights at the location of HW when higher ventilation rates are set, as it can be noted at Figure 2 in view of the temperature profiles obtained.

To sum up it can be noted that ventilation performance IAQ indices, air change efficiency $\left(\varepsilon^{a}\right)$ and local air change index $\left(\varepsilon_{P}^{a}\right)$ in the three points considered, maintain or improve their values lightly with the increase of air ventilation rate.

\subsection{Contaminant distribution}

Contaminant removal effectiveness $\left(\varepsilon^{c}\right)$ is obtained for as a global index of the performance of the ventilation system in removing the emitted contaminants for the three tests performed. The results obtained are shown in Figure 6.

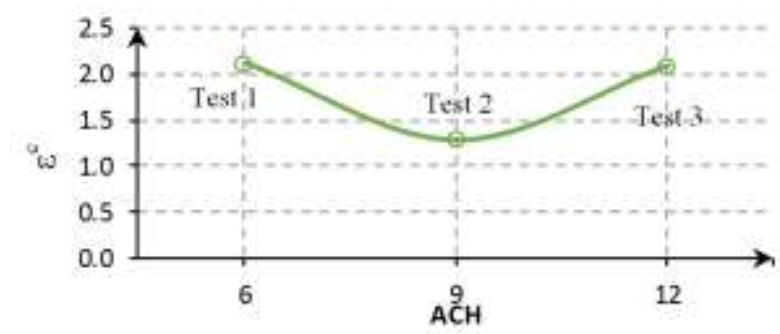

Figure 6. Contaminant removal effectiveness for the three tests performed

According to the results obtained, contaminant removal effectiveness presents values that are greater than 1 for all the three tests performed, as shown in Figure 6. Test 1 and Test 3 values 
are around 2 while Test 2 value is around 1.5. This index is a measure of how quickly air borne contaminants are removed from the chamber. A value higher than 1 means that contaminants remains a short period of time in the room before they are removed by the exhaust, so it can be concluded that the three tests performed remove the emitted contaminants efficiently [15]. The obtained values are comparable to the obtained ones for AIIR where other ventilation strategies are used [22,62]. The value of $\varepsilon^{c}$ is strongly influenced by the position of the source of contaminants $[15,22,45]$. Being the source situated in the same point in all the three tests performed, its variation in Test 2 must be related with a local change in the air flow pattern inside the chamber that reduce the ventilation system performance in this matter.

Tracer gas measurements are used to obtain local contaminant exposition $\left(e_{P}^{c}\right)$, maximum exposure coefficient $\left(e_{P, \max }^{c}\right)$ and its frequency $\left(f_{e_{P, \max }^{c}}\right)$ for the 10 different points considered in this study. These results are shown numerically in Table 5 and have been represented for better understanding in Figure 7 and Figure 8.

Table 5. Local contaminant exposition, maximum exposure coefficient and its frequency in all the 10 considered measurement points.

\begin{tabular}{|c|c|c|c|c|c|c|c|c|c|c|c|}
\hline & & \multicolumn{10}{|c|}{ Tracer gas measurement locations } \\
\hline & & H1 & H2 & H3 & M1 & M2 & M3 & L1 & $\mathbf{L 2}$ & L3 & Inh \\
\hline \multirow{3}{*}{ Test1 } & $e_{P}^{c}$ & 1.10 & 0.45 & 0.33 & 1.97 & 0.48 & 0.35 & 2.57 & 0.18 & 0.36 & 0.36 \\
\hline & $e_{P, \max }^{c}$ & 2.06 & 0.87 & 0.46 & 3.49 & 0.93 & 0.53 & 4.31 & 0.30 & 0.62 & 0.65 \\
\hline & $\boldsymbol{f}_{e_{P \max }^{c}}$ & 4.00 & 2.67 & 1.33 & 6.90 & 6.23 & 4.21 & 5.42 & 1.45 & 2.89 & 7.24 \\
\hline \multirow{3}{*}{ Test 2} & $e_{P}^{c}$ & 2.11 & 1.00 & 0.60 & 1.43 & 0.52 & 0.61 & 2.55 & 0.23 & 0.46 & 0.52 \\
\hline & $e_{P, \max }^{c}$ & 4.29 & 1.86 & 0.93 & 3.20 & 0.99 & 1.04 & 4.69 & 0.45 & 0.73 & 0.93 \\
\hline & $\boldsymbol{f}_{e_{P, \max }^{c}}$ & 5.27 & 3.91 & 1.56 & 4.04 & 4.04 & 2.52 & 4.37 & 1.68 & 2.69 & 4.37 \\
\hline \multirow{3}{*}{ Test 3} & $e_{P}^{c}$ & 1.26 & 1.04 & 0.35 & 3.38 & 0.60 & 0.78 & 0.84 & 0.13 & 0.44 & 0.35 \\
\hline & $e_{P, \max }^{c}$ & 2.33 & 2.10 & 0.58 & 6.06 & 1.58 & 1.36 & 2.26 & 0.17 & 0.91 & 0.78 \\
\hline & & 4.54 & 4.15 & 4.15 & 6.56 & 4.71 & 3.87 & 5.04 & 0.84 & 3.70 & 4.71 \\
\hline
\end{tabular}



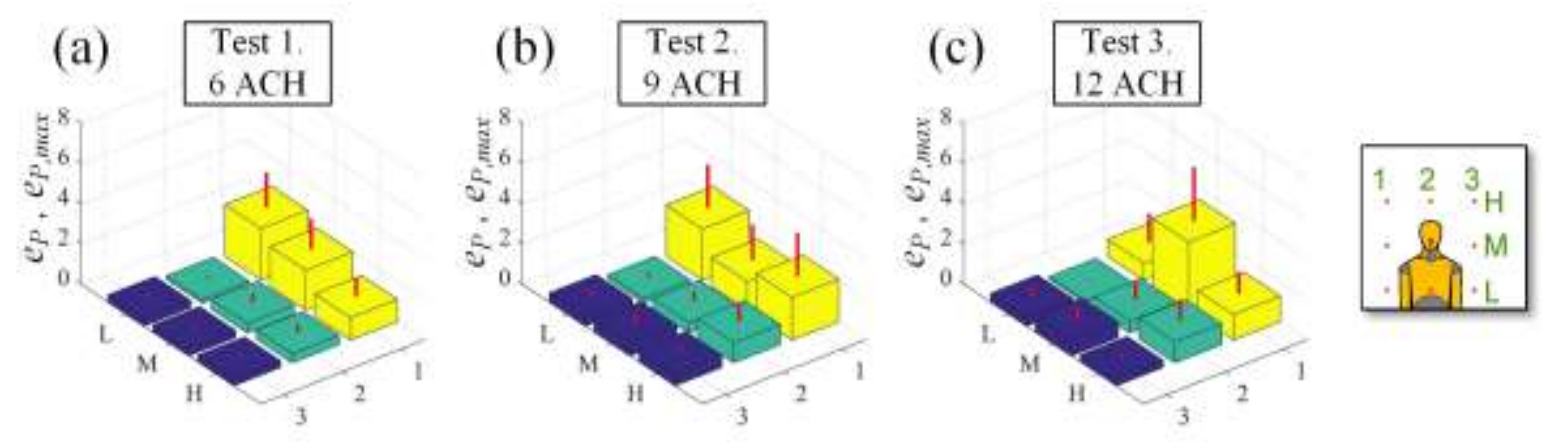

Figure 7. Local Contaminant exposition (bars) together with the corresponding LMEC (red lines) value for the 9-point array situated in HW microenvironment. (a) Test $1.6 \mathrm{ACH}$ ventilation rate; (b) Test 2. $9 \mathrm{ACH}$ ventilation rate; (c) Test $3.12 \mathrm{ACH}$ ventilation rate.

According to the results, exposure to contaminants show different behaviors depending on the position of the probes. Natural convection, due to the difference of temperature of the exhaled flow respect to the ambient temperature of the chamber, combined with exhalation flow momentum and ventilation air movements, are the forces that disperse the contaminants seeded in $\mathrm{P}$ exhalation [66]. In all the three tests performed, the most exposed zone to contaminants is the closest to the exhalation of $\mathrm{P}$, which corresponds with the probes placed in the column 1 as can be seen at Figure 7, the lock-up situation found in smoke tests (Figure 3 (b)) can contribute to this situation. Local maximum exposition values for these three probes are also high. The other two columns maintain, in general, a lower exposition to contaminants, decreasing this value with the distance to the source, as has previously observed in other studies [37,66,72]. The lockup phenomenon observed in Figure 3 (b) can also be the cause of the increase of contaminant exposition with height observed in columns 2 and 3 the three experiments. It can also be noted that an increase of ventilation renovation rate not always leads to a reduction of contaminant exposition, on the contrary, some of the points considered increase its mean and peak exposition. This phenomenon is particularly significant at $\mathrm{M}$ height, which is the height of the inhalation of HW. Contaminant exposition in the immediately closest point to the inhalation point (M2) of HW and the exposition obtained for a point placed into the inhalation airway of HW manikin (Inh) can be compared. 
Exposition to contaminants is always lower in the second case. This is because thermal plume of HW heated body brings clean air from the lower part of the room which is inhaled by HW, reducing the content of contaminants in it, as can be seen at Figure 3. This effect has been already found in other studies [68].
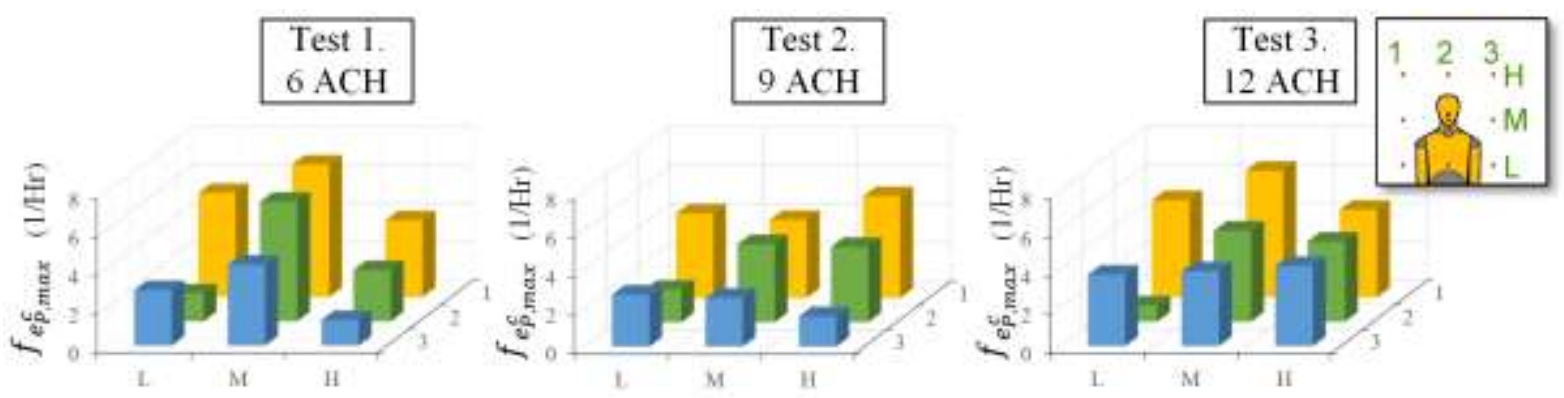

Figure 8. Frequency of maximum exposure coefficients for each test performed

Frequency of maximum exposure coefficients results, Figure 8 and Table 5, show that this index is dependent of the distance to the source of contaminants, but this time the dependence is less intense that in the case of $e_{P}^{c}$ and $e_{P, \max }^{c}$. In general, the points placed closer to the source present higher $f_{e_{P, \max }^{c}}$ values than the ones that are farther which is consistent with the results of $e_{P}^{c}$ and $e_{P, \max }^{c}$, where the same phenomena is found. The dependence of $f_{e_{P, \max }^{c}}$ with air ventilation rate is not as strong as in the case of $e_{P}^{c}$ and $e_{P, \max }^{c}$. Anyway the value of $f_{e_{P, \max }^{c}}$ changes from one test to others. A generalized decrease of $f_{e_{P, \max }^{c}}$ is found when air ventilation rate is increased from Test 1 to Test 2. Although, the increment of air ventilation rate from Test 2 to Test 3 make values of $f_{e_{P, \max }^{c}}$ similar to the obtained in Test 1 . This results suggest that an increase of air ventilation rate over certain value doesn't have a positive impact on $f_{e_{P, \max }^{c}}$. 
Proportional contaminants intake referred to the average concentration of the emission source of contaminants has been obtained for each test performed in the inhalation area of the $\mathrm{P}$ manikin. This index has been obtained in two different points, immediately in front to of the inhalation point (M2), and inside the inhalation airways of the manikin (Inh). Results are shown in Figure 9.

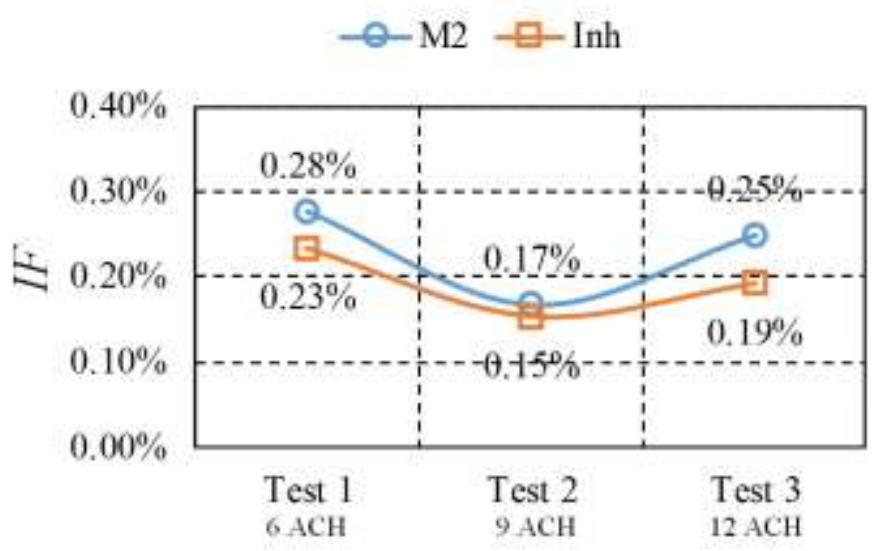

Figure 9. Proportional contaminants intake referred to the concentration of the only source of contaminants, P breathing.

According to the results shown in Figure 9, the tendency of $I F$ for the three tests performed the same in the two positions considered. Even so, the values obtained for the point Inh are always lower than the obtained in the point M2, the same way $\varepsilon_{P}^{c}$ index in these points behave. This results suggest that by selecting a point out of the inhalation airways to determine the contaminants intake of the manikin, the resulting index could be overestimated [63]. This may be originated by the action of the human convective boundary layer that drags clean air from the lower part of the room as can be seen at

Figure 3 . This situation has been already seen in other studies $[69,73]$. If the development of IF for the three test performed is considered, the higher values for this index are always obtained when the lower ventilation rate is performed, Test 1 . The increase of the ventilation rate from Test 1 to Test 2 reduce the value of $I F$, and thus the contaminants intake of the HW manikin decreases. Although, when the ventilation rate is increased again from Test 2 to Test 3 , the tendency changes, and the obtained values for Test 3 are comparable to the obtained in Test 1 . The behavior of $I F$ in the three different tests carried out show that the increase of the ventilation rate over a certain value have a negative impact on $I F$. 


\section{Conclusions}

Experimental tests have been carried out to determine thermal comfort, ventilation performance and contaminant exposition in a typical AIIR configuration using displacement ventilation strategy. Three air ventilation rates have been tested to determine its impact on these three issues. In view of the results of each test and the comparisons between them, the following conclusions can be stated:

- According to the general comfort indices obtained for the three experiments carried out, the two occupants have different thermal sensations under the same ambient conditions, while HW identifies a hot environment, PP registers a cold one. It is due to their different metabolic rates originated by their different level of activity. It can be noted that the air ventilation rates tested in this experimental study have an impact on the environment conditions of the experimental chamber and thus on the comfort situation of the people inside it. The increase of air ventilation rate promotes air temperature homogeneity in the low part of the chamber, decreasing ambient temperature difference between the head and the feet of the manikins and thus improving thermal comfort according to operative temperature $\left(T_{o}\right)$ index.

- Contaminant removal effectiveness $\left(\varepsilon^{c}\right)$ maintains a high effective performance value for the three tests performed. Ventilation performance IAQ indices, air change efficiency $\left(\varepsilon^{a}\right)$ and local air change index $\left(\varepsilon_{P}^{a}\right)$, maintain acceptable values in general terms. Nevertheless, the performance of these values is not proportional to the air ventilation rate set in each test. In fact, and on the contrary it might be though, the increase of air ventilation rate has a negative impact on some of these values. The same way, an increase of air ventilation rate not always lead to a reduction of contaminant exposition. In most points around the inhalation point of the HW, included the closest point to the inhalation, the exposition to contaminants increase. 
So, according to these values, an increase of air ventilation rate over certain values doesn't necessarily mean an improvement on ventilation performance and couldn't be justified on these terms when displacement ventilation strategy is used.

- A "lock-up" phenomenon has been identified at a height above of $\mathrm{P}$ head. This situation can promote the increase of contaminant concentration under this height. This situation does affect, but not significantly, the exposition of the different points around HW inhalation. This lack of affection is due to the effect of the convective boundary layer, which provides fresh air from the lower part or the chamber to the inhalation zone of $\mathrm{HW}$, avoiding the penetration of contaminants in HW microenvironment. The different experiments carried out suggest that this phenomenon is undermined by the increase of air ventilation rate, increasing the exposition to contaminants of HW.

- The exposition to contaminants $\left(\varepsilon_{P}^{c}\right)$ in a point around HW inhalation is dependent of its position respect to the source. In general, the closer points from the source present a higher contaminant concentration. Likewise, the maximum peak exposition and the its frequency in such points is higher than in the rest of the considered points.

- Intake fraction $I F$ and local contaminant exposition indices $\left(\varepsilon_{P}^{c}\right)$ show that the contaminant concentration in the surroundings of the inhalation point is always higher than the obtained in the inhalation airways. So, an overestimation of the real exposition to contaminants

Considering all the results, this paper shows that displacement ventilation is a real alternative to mixing ventilation as strategy for AIIRs. Comfort for patients and health workers can be achieved as well as acceptable IAQ indices and HW contaminant exposition by using this strategy the same way it could be done by using mixing ventilation. However, and according to the results, high ventilation rates such as the recommended ones in the consulted guides for 
AIIRs design (12 ACH or more) are not justified when strategy displacement ventilation is selected. The situation sets the necessity of distinguish the different ventilation strategies when an air ventilation rate is recommended. It also draws attention, in a more general point of view, on the necessity of extend the recommendations about ventilation in AIIRs not only in the air ventilation rate but in other aspects such as the distribution of the room or the position of the thermal loads that, at the end, determines how the air distributes inside the room.

\section{References}

[1] M.-F. King, C.J. Noakes, P. a Sleigh, Modeling environmental contamination in hospital single- and four-bed rooms., Indoor Air. (2015) 1-14. doi:10.1111/ina.12186.

[2] C.B. Beggs, L.D. Knibbs, G.R. Johnson, L. Morawska, Environmental contamination and hospital-acquired infection: factors that are easily overlooked, Indoor Air. 25 (2015) 462-474. doi:10.1111/ina.12170.

[3] J. Richmond-Bryant, Transport of exhaled particulate matter in airborne infection isolation rooms, Build. Environ. 44 (2009) 44-55. doi:10.1016/j.buildenv.2008.01.009.

[4] L. Liu, Y. Li, P. V. Nielsen, J. Wei, R.L. Jensen, Short-range airborne transmission of expiratory droplets between two people, Indoor Air. (2016) 1-11. doi:10.1111/ina.12314.

[5] S. Stelzer-Braid, B.G. Oliver, A.J. Blazey, A. Elizabeth, T.P. Newsome, W.D. Rawlinson, et al., Exhalation of respiratory viruses by breathing, coughing, and talking, J. Med. Virol. 81 (2009) 1674-1679. doi:10.1002/jmv.

[6] D.K. Milton, M.P. Fabian, B.J. Cowling, M.L. Grantham, J.J. McDevitt, Influenza virus aerosols in human exhaled breath: particle size, culturability, and effect of surgical masks, PLoS Pathog. 9 (2013) e1003205. doi:10.1371/journal.ppat.1003205.

[7] F.A. Berlanga, I. Olmedo, M. Ruiz de Adana, Experimental analysis of the air velocity and contaminant dispersion of human exhalation flows, Indoor Air. (2016) 1-13. doi:10.1111/ina.12357.

[8] J.K. Gupta, C.H. Lin, Q. Chen, Flow dynamics and characterization of a cough, Indoor Air. 19 (2009) 517-525. doi:10.1111/j.1600-0668.2009.00619.x.

[9] J. Tang, A. Nicolle, C. Klettner, J. Pantelic, L. Wang, A. Suhaimi, et al., Airflow dynamics of human jets: sneezing and breathing - potential sources of infectious aerosols, PLoS One. 8 (2013) e59970. doi:10.1371/journal.pone.0059970.

[10] X. Xie, Y. Li, A.T.Y. Chwang, P.L. Ho, W.H. Seto, How far droplets can move in indoor environments - revisiting the Wells evaporation-falling curve, Indoor Air. 17 (2007) 211-225. doi:10.1111/j.1600-0668.2007.00469.x.

[11] W.F. Wells, On air-borne infection. II. Droplets and droplet nuclei, Am. J. Hyg. 20 (1934) 611-618.

[12] A. Jurelionis, L. Gagytè, T. Prasauskas, D. Čiužas, E. Krugly, L. Šeduikytė, et al., The impact of the air distribution method in ventilated rooms on the aerosol particle dispersion and removal: The experimental approach, Energy Build. 86 (2015) 305313. doi:http://dx.doi.org/10.1016/j.enbuild.2014.10.014. 
[13] K. Lyngby, T.H. Kuehn, H.E.B. Burroughs, C.O. Muller, D. Tompkins, W.J. Fisk, et al., ASHRAE Position Document on Approved by ASHRAE Board of Directors, (2015).

[14] M.P. Atkinson, L.M. Wein, Quantifying the routes of transmission for pandemic influenza, Bull. Math. Biol. 70 (2008) 820-867. doi:10.1007/s11538-007-9281-2.

[15] E. Mundt, H.M. Mathisen, P. V. Nielsen, A. Moser, Ventilation Effectiveness, 2004.

[16] J.D. Siegel, E. Rhinehart, M. Jackson, L. Chiarello, 2007 Guideline for Isolation Precautions: Preventing Transmission of Infectious Agents in Health Care Settings, Am. J. Infect. Control. 35 (2007). doi:10.1016/j.ajic.2007.10.007.

[17] N.J. Adams, D.L. Johnson, R. a. Lynch, The effect of pressure differential and care provider movement on airborne infectious isolation room containment effectiveness, Am. J. Infect. Control. 39 (2011) 91-97. doi:10.1016/j.ajic.2010.05.025.

[18] E. Lingaas, J.P. Rydock, Best practice in design and testing of isolation rooms in Nordic hospitals, Round Table Ser. - R. Soc. Med. (2007) 87-107.

[19] Victorian Advisory Committee on Infection Control, Guidelines for the classification and design of isolation rooms in health care facilities, 1st ed., Victorian Government, Melbourne, 2007.

[20] Centers for Disease Control and Prevention, Guidelines for preventing the transmission of Mycobacterium tuberculosis in health-care facilities., MMWR Morb Mortal Wkly Rep. 43 (1994) 1-132. doi:10.2307/42000931.

[21] L. Sehulster, R.Y.W. Chinn, Guidelines for environmental infection control in healthcare facilities, Morb. Mortal. Wkly. Rep. 52 (2003) 1-42.

[22] F. Memarzadeh, W. Xu, Role of air changes per hour (ACH) in possible transmission of airborne infections, Build. Simul. 5 (2012) 15-28. doi:10.1007/s12273-011-0053-4.

[23] P. Kalliomäki, P. Saarinen, J.W. Tang, H. Koskela, Airflow patterns through single hinged and sliding doors in hospital isolation rooms - Effect of ventilation, flow differential and passage, Build. Environ. $107 \quad$ (2016) 154-168. doi:10.1016/j.buildenv.2016.07.009.

[24] A. Jurelionis, L. Gagyte, L. Seduikyte, T. Prasauskas, D. Ciuzas, D. Martuzevicius, Combined air heating and ventilation increases risk of personal exposure to airborne pollutants released at the floor level, Energy Build. 116 (2016) 263-273. doi:10.1016/j.enbuild.2016.01.011.

[25] P. Kumar, C. Martani, L. Morawska, L. Norford, R. Choudhary, M. Bell, et al., Indoor air quality and energy management through real-time sensing in commercial buildings, Energy Build. 111 (2016) 145-153. doi:10.1016/j.enbuild.2015.11.037.

[26] A. Kabanshi, H. Wigö, M. Sandberg, Experimental evaluation of an intermittent air supply system - Part 1: Thermal comfort and ventilation efficiency measurements, Build. Environ. 95 (2016) 240-250. doi:10.1016/j.buildenv.2015.09.025.

[27] W. Yu, B. Li, H. Jia, M. Zhang, D. Wang, Application of multi-objective genetic algorithm to optimize energy efficiency and thermal comfort in building design, Energy Build. 88 (2015) 135-143. doi:10.1016/j.enbuild.2014.11.063.

[28] F. Memarzadeh, A. Manning, Thermal comfort, uniformity, and ventilation effectiveness in patient rooms: performance assessment using ventilation indices, ASHRAE Trans. 106 (2000).

[29] R. Van Gaever, V.A. Jacobs, M. Diltoer, L. Peeters, S. Vanlanduit, Thermal comfort of the surgical staff in the operating room, Build. Environ. 81 (2014) 37-41. doi:10.1016/j.buildenv.2014.05.036.

[30] C.A. Balaras, E. Dascalaki, A. Gaglia, HVAC and indoor thermal conditions in hospital operating rooms, Energy Build. $39 \quad$ (2007) 454-470. doi:10.1016/j.enbuild.2006.09.004. 
[31] S. Del Ferraro, S. Iavicoli, S. Russo, V. Molinaro, A field study on thermal comfort in an Italian hospital considering differences in gender and age, Appl. Ergon. 50 (2015) 177-184. doi:10.1016/j.apergo.2015.03.014.

[32] L. Lan, L. Pan, Z. Lian, H. Huang, Y. Lin, Experimental study on thermal comfort of sleeping people at different air temperatures, Build. Environ. 73 (2014) 24-31. doi:10.1016/j.buildenv.2013.11.024.

[33] S. Zhu, W. Cai, J.D. Spengler, Control of sleep environment of an infant by widecover type personalized ventilation, Energy Build. 129 (2016) 69-80. doi:10.1016/j.enbuild.2016.07.064.

[34] P.O. Fanger, Thermal comfort: analysis and applications in environmental engineering, McGraw-Hill, 1970.

[35] AEN/CTN 81, UNE-EN ISO 7730. Ergonomía en ambiente térmico. Determinación analítica e interpretación del bienestar térmico mediante el cálculo de los índices PMV y PPD y los criterios de bienestar térmico local, Madrid, 2006.

[36] J.M. Villafruela, I. Olmedo, M. Ruiz de Adana, C. Méndez, P. V. Nielsen, CFD analysis of the human exhalation flow using different boundary conditions and ventilation strategies, Build. Environ. 62 (2013) 191-200. doi:10.1016/j.buildenv.2013.01.022.

[37] Y.C. Tung, S.C. Hu, T.I. Tsai, I.L. Chang, An experimental study on ventilation efficiency of isolation room, Build. Environ. 44 (2009) 271-279. doi:10.1016/j.buildenv.2008.03.003.

[38] X. Ye, H. Zhu, Y. Kang, K. Zhong, Heating energy consumption of impinging jet ventilation and mixing ventilation in large-height spaces: A comparison study, Energy Build. 130 (2016) 697-708. doi:10.1016/j.enbuild.2016.08.055.

[39] M. Behne, Indoor air quality in rooms with cooled ceilings. Mixing ventilation or rather displacement ventilation?, Energy Build. 30 (1999) 155-166. doi:10.1016/S0378-7788(98)00083-8.

[40] N.M. Mateus, G.C. Da Graça, Simplified modeling of displacement ventilation systems with chilled ceilings, Energy Build. 108 (2015) 44-54. doi:10.1016/j.enbuild.2015.08.054.

[41] E. Mundt, Contamination distribution in displacement ventilation-influence of disturbances, Build. Environ. 29 (1994) 311-317. doi:10.1016/0360-1323(94)90028-0.

[42] S. Cho, P. Im, J.S. Haberl, Literature Review of Displacement Ventilation, Energy Syst. Lab. Texas A\&M Univ. Syst. (2005) 23.

[43] D. Spengler, J.M. Samet, J.F. McCarthy, Disinfecting air, in: Indoor Air Qual. Handb., 2001.

[44] J. Wang, Y. Chen, Concentration characteristics of ozone and product for indoor occupant surface chemical reaction under displacement ventilation, Energy Build. 130 (2016) 378-387. doi:10.1016/j.enbuild.2016.08.065.

[45] R. Tomasi, M. Krajčík, A. Simone, B.W. Olesen, Experimental evaluation of air distribution in mechanically ventilated residential rooms: Thermal comfort and ventilation effectiveness, Energy Build. $60 \quad$ (2013) 28-37. doi:10.1016/j.enbuild.2013.01.003.

[46] J.P. Rydock, P.K. Eian, Containment testing of isolation rooms, J. Hosp. Infect. 57 (2004) 228-232. doi:10.1016/j.jhin.2004.01.032.

[47] D. Than, J. Decker, Case Studies: Evaluation of Isolation Rooms in Health Care Settings Using Tracer Gas Analysis, Appl. Occup. Environ. Hyg. 10 (1995) 887-891. doi:10.1080/1047322X.1995.10387707.

[48] J. Yang, S.C. Sekhar, K.W.D. Cheong, B. Raphael, Performance evaluation of a novel personalized ventilation-personalized exhaust system for airborne infection control, 
Indoor Air. 25 (2015) 176-187. doi:10.1111/ina.12127.

[49] Y. Yin, W. Xu, J.K. Gupta, A. Guity, P. Marmion, A. Manning, et al., Experimental Study on Displacement and Mixing Ventilation Systems for a Patient Ward, HVAC\&R Res. 15 (2009) 1175-1191. doi:10.1080/10789669.2009.10390885.

[50] H. Qian, Y. Li, P. V. Nielsen, C.E. Hyldgaard, T.W. Wong, a T.Y. Chwang, Dispersion of exhaled droplet nuclei in a two-bed hospital ward with three different ventilation systems, Indoor Air. 16 (2006) 111-28. doi:10.1111/j.16000668.2005.00407.x.

[51] A. Guity, M. Nash, L. Burch, P. Marmion, Healthcare Ventilation Research Collaborative : Displacement Ventilation, (2009).

[52] H. Qian, Y. Li, Removal of exhaled particles by ventilation and deposition in a multibed airborne infection isolation room, Indoor Air. 20 (2010) 284-297. doi:10.1111/j.1600-0668.2010.00653.x.

[53] C.W. Branch, Building and Refurbishment: Infection Control Guidelines January 2002, 2009.

[54] F.A. Berlanga, M. Ruiz de Adana, I. Olmedo, Diseño y construcción de maniquíes térmicos para la realización de ensayos experimentales de sistemas de climatización, in: Proc. IX Congr. Nac. Ing. Termodinámica, Cartagena, 2015: pp. 1-8. doi:978-84606-8931-7.

[55] American Society of Heating and Air-Conditioning Engineers; , Thermal Comfort, in: ASHRAE Handb. Fundam. 2013, Atlanta, GA, 2013: p. 9.1-9.32.

[56] S. Tanabe, E.A. Arens, F.. Bauman, H. Zang, T.. Madsen, Evaluating thermal environments by using a thermal manikin with controlled skin surface temperature, Ashrae Trans. 1994. 100 (1994) 39-47.

[57] J.K. Gupta, C.-H. Lin, Q. Chen, Characterizing exhaled airflow from breathing and talking, Indoor Air. 20 (2010) 31-9. doi:10.1111/j.1600-0668.2009.00623.x.

[58] Technical Comitee for Ergonomics of the physical environment, ISO 7726 Ergonomics of the thermal envinonment - Instruments for measuring physical quantities, 2nd ed., ISO, 1998.

[59] M. Krajčík, A. Simone, B.W. Olesen, Air distribution and ventilation effectiveness in an occupied room heated by warm air, Energy Build. 55 (2012) 94-101. doi:10.1016/j.enbuild.2012.08.015.

[60] H.B. Awbi, Ventilation of buildings, 2nd ed., Spon Press, London, 2003. doi:10.1080/02786820490519234.

[61] H. Amai, A. Novoselac, Experimental study on air change effectiveness in mixing ventilation, Build. Environ. 109 (2016) 101-111. doi:10.1016/j.buildenv.2016.09.015.

[62] J.M. Villafruela, F. Castro, J.F. San Jose, J. Saint-Martin, Comparison of air change efficiency, contaminant removal effectiveness and infection risk as IAQ indices in isolation rooms, Energy Build. 57 (2013) 210-219. doi:10.1016/j.enbuild.2012.10.053.

[63] J. Laverge, M. Spilak, A. Novoselac, Experimental assessment of the inhalation zone of standing, sitting and sleeping persons, Build. Environ. 82 (2014) 258-266. doi:10.1016/j.buildenv.2014.08.014.

[64] W.G. Lindsley, W.P. King, R.E. Thewlis, J.S. Reynolds, K. Panday, G. Cao, et al., Dispersion and exposure to a cough-generated aerosol in a simulated medical examination room., J. Occup. Environ. Hyg. 9 (2012) 681-90. doi:10.1080/15459624.2012.725986.

[65] G. Cao, P. V. Nielsen, R.L. Jensen, P. Heiselberg, L. Liu, J. Heikkinen, Protected zone ventilation and reduced personal exposure to airborne cross-infection, Indoor Air. 25 (2015) 307-319. doi:10.1111/ina.12142.

[66] I. Olmedo, P. V. Nielsen, M. Ruiz de Adana, R.L. Jensen, P. Grzelecki, Distribution of 
exhaled contaminants and personal exposure in a room using three different air distribution strategies., Indoor Air. 22 (2012) 64-76. doi:10.1111/j.16000668.2011.00736.x.

[67] J. Pantelic, K.W. Tham, D. Licina, Effectiveness of a personalized ventilation system in reducing personal exposure against directly released simulated cough droplets, Indoor Air. 25 (2015) 683-693. doi:10.1111/ina.12187.

[68] D. Licina, A.K. Melikov, C. Sekhar, K.W. Tham, Human convective boundary layer and its interaction with room ventilation flow., Indoor Air. 25 (2015) 1-15. doi:10.1111/ina.12120.

[69] D. Licina, A. Melikov, C. Sekhar, K.W. Tham, Transport of Gaseous Pollutants by Convective Boundary Layer around a Human Body, Sci. Technol. Built Environ. (2015) 00-00. doi:10.1080/23744731.2015.1060111.

[70] C. Xu, P. V. Nielsen, G. Gong, R.L. Jensen, L. Liu, Influence of air stability and metabolic rate on exhaled flow, Indoor Air. 25 (2015) 198-209. doi:10.1111/ina.12135.

[71] J.W. Tang, Y. Li, I. Eames, P.K.S. Chan, G.L. Ridgway, Factors involved in the aerosol transmission of infection and control of ventilation in healthcare premises, J. Hosp. Infect. 64 (2006) 100-114. doi:10.1016/j.jhin.2006.05.022.

[72] E. Bjørn, P. V. Nielsen, Dispersal of exhaled air and personal exposure in displacement ventilated rooms, Indoor Air. 12 (2002) 147-64.

[73] S. Zhu, S. Kato, S. Murakami, T. Hayashi, Study on inhalation region by means of CFD analysis and experiment, Build. Environ. 40 (2005) 1329-1336. doi:10.1016/j.buildenv.2004.11.009. 